\title{
Effect of phosphonoacetic acid in the treatment of experimental herpes simplex keratitis
}

\author{
YITZCHAK J. GORDON, MOSHE LAHAV, SOTERAKIS PHOTIOU, AND \\ YECHIEL BECKER \\ From the Department of Ophthalmology, Laboratory for Molecular Biology, Hebrew University-Hadassah \\ Medical School, Jerusalem, Israel
}

SUMMARY In the rabbit $5 \%$ phosphonoacetic acid ointment suppressed herpetic keratitis as well as $0.5 \%$ idoxuridine ointment. After 5 days of treatment quantitative virus titres showed that phosphonoacetic acid was superior to idoxuridine in the inhibition of herpes virus replication. Phosphonoacetic acid was found to be nontoxic to the eye in both clinical and histopathological studies. Recent reports suggest that the mechanism of action of phosphonoacetic acid appears to be the blocking of the virus DNA polymerase, which is essential for the synthesis of herpes virus DNA.

Over 16 years ago Kaufman et al. (1961) introduced idoxuridine (IDU) to clinical ophthalmology, and it is still considered the drug of choice in the treatment of herpetic keratitis. However, owing to the emergence of IDU-resistant strains (Coleman et al., 1968; Jawetz et al., 1970; Hyndiuk et al., 1972; O'Day et al., 1976), toxicity (Peterson and Jones, 1967; O'Day and Jones, 1977), and failure to prevent recurrences (Kaufman et al., 1962; Carroll et al., 1967) alternative therapeutic regimens are being investigated. Phosphonoacetic acid (PAA) was first reported by Shipkovitz et al. (1973) to inhibit herpes simplex in tissue culture as well as to suppress herpetic dermatitis in mice and prevent keratitis in rabbits. Gerstein et al. (1975) demonstrated in the rabbit that $5 \%$ PAA was equivalent to $0.5 \%$ IDU in suppressing established experimental keratitis. Meyer et al. (1976) showed that PAA was as effective as IDU in the treatment of experimental epithelial keratitis. Furthermore he showed that PAA was effective against IDUresistant keratitis when applied topically and against herpetic iritis when administered subconjunctivally and intravenously. In view of the promising nature of this agent further studies were indicated.

The purposes of the present study are (1) to compare the effects of PAA and IDU on the suppression of established keratitis in the rabbit, (2) to compare the relative efficacy of PAA and IDU in vivo with respect to the inhibition of virus replication as determined by quantitative virus titrations, (3) to evaluate toxicity of PAA both clinically and histopathologically, and (4) to compare the mode of

Address for reprints: Dr Y. J. Gordon, PO Box MS751, Maseru, Lesotho. action of PAA and IDU as antiherpetic agents, and review their relative theoretical advantages and limitations.

\section{Materials and methods}

A total of 36 mongrel rabbits weighing 1.5 to $2.5 \mathrm{~kg}$ were used in this study. All eyes were examined prior to inoculation and found to be free of corneal disease. Both corneas were anaesthetised and superficially scarified with a blunt No. 19 needle in a cross pattern, care being taken not to injure the corneal stroma. Virus inoculation was done with $0.15 \mathrm{ml}$ of virus stock solution dripped over the cornea. The lids were then closed and rubbed over the corneas for 30 seconds. The virus used was herpes simplex, type 1, NIH strain No. 11124, at a concentration of $2.0 \times 10^{7} \mathrm{pfu} / \mathrm{ml}$ which had been maintained in tissue culture by multiple passages in BSC-1 cell monolayers. Two days after infection typical dentritic keratitis was established in all eyes, and the severity of keratitis in each cornea was graded. The animals were then divided into three comparable groups based on the severity of the keratitis and randomly assigned to 3 treatment groups. The drugs were coded so that neither the examiner nor the person treating the animals was aware of which drug the animals received. Treatment was administered to each animal 4 times per day with the instillation of $1 \mathrm{~cm}$ of drug ointment into the lower fornix of both eyes beginning on the second day after infection and continuing for 5 days. The drugs tested included (a) petrolatum base as control, (b) $5 \%$ phosphonoacetic acid (disodium salt in petrolatum base, $\mathrm{pH} \mathrm{7.0,} \mathrm{courtesy} \mathrm{of} \mathrm{Abbott}$ Laboratories, North Chicago, USA), and (c) $0.5 \%$ 
idoxuridine ointment (standard preparation). All animals were graded daily by the same examiner using a 3-power magnifier, $0 \cdot 12 \%$ fluorescein, and cobalt blue filter. The severity of the keratitis was graded on a scale of 0 to 4 (modified from Lahav et al., 1975).

Grade 0. No keratitis.

Grade 1 . Five to 10 small dendrites initially limited to the epithelium along the lines of abrasion with no stromal involvement.

Grade 2. Ten to 20 dendrites or confluent ulcer involving less than one-third of the cornea with or without stromal involvement.

Grade 3. Confluent or multiple dendritic corneal ulcers involving more than one-third but less than two-thirds of the corneal surface with stromal involvement.

Grade 4. Confluent or multiple dendritic corneal ulcers involving more than two-thirds of the corneal surface with stromal involvement.

Virus cultures were taken after grading but prior to treatment on days 2,7 , and 10 by rolling a sterile cotton swab from the upper fornix across the cornea into the lower fornix. The samples were placed in sterile tissue culture media at $+4^{\circ} \mathrm{C}$ and then frozen and stored at $-60^{\circ} \mathrm{C}$. Virus samples were coded so that the person who performed the analyses was unaware of the experimental design. Virus titration was later accomplished by thawing the frozen samples, carrying out serial 10 -fold dilutions of each sample, and inoculation on BSC-1 cell monolayers. Cytopathic plaque formation was observed, and quantitated according to the method of Levitt and Becker (1967). The experiments were terminated on the twelfth day after infection. After the virus titrations were accomplished all codes were broken, and the data were analysed statistically by Student's $t$ test.

\section{Results}

The effect of different treatment regimens on the course of herpetic keratitis is summarised in Fig. 1.

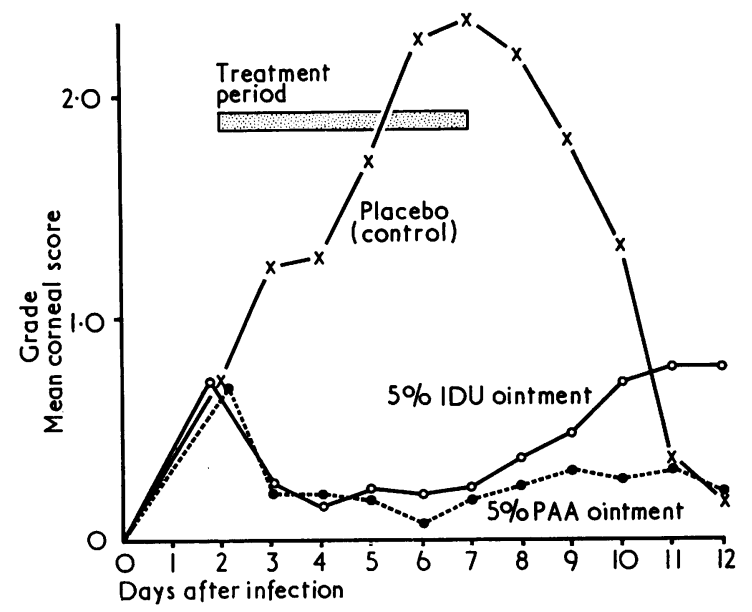

Fig. 1 Effect of PAA, IDU, and placebo on the severity of herpetic keratitis in rabbits. Each point represents the mean corneal score for all rabbits in each treatment category on the day indicated

The herpetic keratitis of the control group reaches its maximum severity 1 week after infection followed by a gradual resolution of the keratitis over the following week. This experimental model is similar to other studies in which the disease is generally self-limited. Treatment with both $5 \%$ PAA and $0.5 \%$ IDU had a profound inhibitory effect on the severity of the clinical epithelial keratitis in rabbits. Table 1 , which summarises the results of several experiments, shows that the observed differences between the control group and the PAA and IDU-treated groups are very highly significant $(P<0.001)$ during the 5-day treatment period. PAA and IDU are equally effective in their suppression of herpetic keratitis during the 5-day treatment period, and there is no statistically significant difference between them. After cessation of treatment the previously reported 'rebound' phenomenon in the IDU-treated group was observed

Table 1 Effect of different treatment regimens on herpetic keratitis

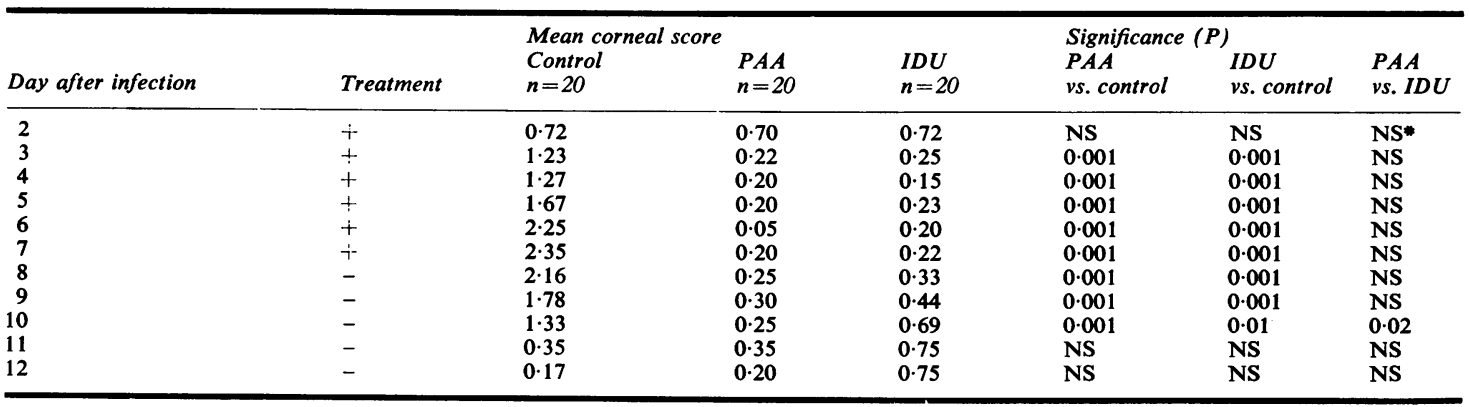

"NS = not significant. 


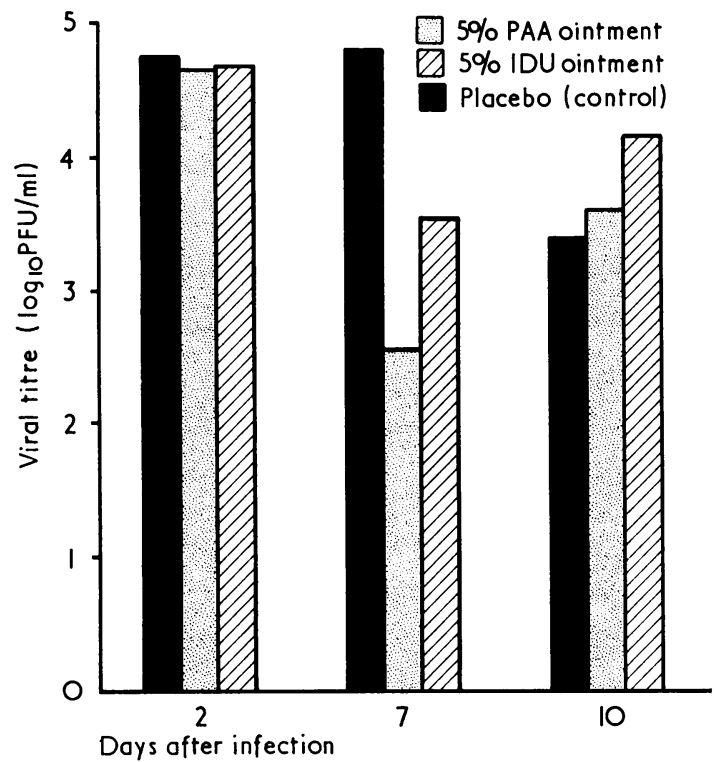

Fig. 2 Effect of $P A A, I D U$, and placebo on the quantitative viral titres of herpes simplex during the course of experimental keratitis in rabbits. Day 2 after infection, before treatment; day 7 after infection, 5 days of treatment; day 10 after infection, 3 days off treatment

(Fig. 1). There appears to have been less rebound in the PAA-treated group, and on day 10, 3 days after cessation of therapy, the keratitis in the PAAtreated group was significantly less $(P<0.02)$ than in the IDU-treated group (Table 1).

The results of the virus titration studies are shown by a representative experiment (Fig. 2). Before treatment all three groups had similar virus titres. After 5 days of treatment there was a $2 \log$ diminution in virus titre in the PAA-treated group with less of an inhibitory effect observed in the IDUtreated group. On day 10 after infection, 3 days off the treatment, the control group showed a marked drop in virus titre, which represented recovery from the infection. In contrast, the PAA and IDUtreated groups both showed a rebound phenomenon, an increase in virus titre off therapy, with the IDUtreated group having a higher titre than the PAAtreated group. Table 2 represents a summary of the virus studies in several experiments. There is no significant difference in the 3 groups before treatment. On day 7, after 5 days of treatment, both the PAA- and IDU-treated groups were significantly better $(P<0.001)$ than the control group. It should be emphasised that PAA was found to be significantly more effective $(P<0.001)$ than IDU in reducing herpes virus replication. Finally, at 10 days both treatment groups again show a rebound off therapy, with the IDU-treated group having a significantly higher $(\mathbf{P}<0.001)$ titre than the PAA-treated group.

Toxicity of $5 \%$ PAA ointment was examined by treating 6 unscarified rabbit corneas 4 times a day for 42 days. Slit-lamp examinations revealed no blepharoconjunctivitis, punctate keratitis, iritis, cataract, or vitreitis. Eyes taken from these animals for routine histopathology had no signs of inflammation or toxic reaction in the anterior or posterior segments.

\section{Discussion}

The results of the present study suggest that phosphonoacetic acid is an effective, new antiherpetic agent. The virus titre generally reflected the severity of herpetic keratitis. It should be emphasised that, although there was no significant difference in the ability of PAA as compared to IDU to inhibit herpetic keratitis during the 5-day treatment period, there was a significant difference in the ability of these 2 drugs to inhibit virus replication as compared to the control during the same period. Quantitative virus titrations showed that PAA was clearly superior to IDU in reducing multiplication of herpes virus.

The current study confirmed the previous work of Gerstein et al. (1975) and Meyer et al. (1976) that PAA is as effective as IDU in inhibiting herpetic keratitis in the rabbit. Gerstein et al. (1975) also reported that virus was isolated in fewer PAA-treated animals than controls after 5 days of treatment. However, as he did not report quantitative virus titrations, nor compare PAA with IDU immediately after treatment, he was unable to assess the relative efficacy of the two drugs. Our study has shown that PAA is significantly better than IDU in reducing virus replication after 5 days of treatment. Three days after cessation of therapy Gerstein observed a

Table 2 Quantitative viral titres in treated herpetic keratitis

\begin{tabular}{|c|c|c|c|c|c|c|}
\hline Day after infection & $\begin{array}{l}\text { Mean } P F U^{*} / \text { Eye } \\
\text { Control } \\
n=20\end{array}$ & $\begin{array}{l}P A A \\
n=20\end{array}$ & $\begin{array}{l}I D U \\
n=20\end{array}$ & $\begin{array}{l}\text { Significance }(P) \\
P A A \\
\text { vs. control }\end{array}$ & $\begin{array}{l}\text { IDU } \\
\text { vs. control }\end{array}$ & $\begin{array}{l}P A A \\
\text { vs. } I D U\end{array}$ \\
\hline
\end{tabular}

"Plaque-forming units. $†$ Not significant. 
rebound phenomenon, with no difference between the PAA- and the IDU-treated animals regarding the ability to isolate virus from them. We have observed a similar rebound phenomenon after cessation of therapy, but again found that the PAA-treated group had significantly lower virus titres than the IDU-treated group.

Toxicity was observed by Gerstein et al. (1975), who reported that $5 \%$ PAA solution administered 8 times a day was associated with a fine, superficial punctate keratitis, but when it was given 4 times a day no toxicity was observed. Meyer et al. (1976) reported that $5 \%$ PAA solution administered topically 6 times a day for 5 days was not toxic to the corneal epithelium. Similarly we have observed that $5 \%$ PAA ointment given 4 times a day for 42 days was unassociated with any clinical toxicity. Furthermore histopathological examination of PAA-treated eyes was within normal limits.

The mode of action of IDU is basically that of an antimetabolite. As a thymidine analogue, IDU is incorporated into the replicating virus DNA in place of thymidine. The resulting DNA is defective and unable to code for virus proteins. Therefore assembly and production of further virus is prevented. However, in addition to its incorporation into virus DNA, IDU is also incorporated into host cell DNA. The clinical toxicity of IDU is attributed to this latter mechanism. Cheng et al. (1975) have suggested that a desirable antiherpetic agent would be one which is not incorporated into host cell DNA.

The mechanism of action of PAA was first reported by Overby et al. (1974) to be inhibition of virus DNA synthesis. Mao and Robishaw (1975) demonstrated in vitro that PAA was a noncompetitive inhibitor of herpetic virus-induced DNA polymerase. This is the critical enzyme which the herpetic virus requires to produce progeny DNA from the initial DNA template. Furthermore, Mao and Robishaw (1975) reported that PAA had no effect on cellular DNA polymerase in several different cell lines. One implication of this finding is that PAA could selectively inhibit the herpes virus without damaging normal host cells. Leinbach et al. (1976) further clarified the mechanism of action of PAA by demonstrating in vitro that PAA inhibited the virus DNA polymerase by interfering with it at the pyrophosphate binding site. This interference favoured an alternative reaction and thereby diminished the polymerisation of the virus DNA. Furthermore, PAA was also found to have no effect on cellular DNA polymerase of several cell lines and minimal effect on others. Therefore the current literature suggests that unlike IDU, whose toxicity is thought to be due to its incorporation into host cell DNA, PAA does not appear to be significantly toxic to normal cells in vitro. However, one of the potential limitations of PAA is the emergence of resistant strains of herpes virus, which have already been produced in tissue culture systems (Hay and Subak-Sharpe, 1976; Becker et al., 1977). Despite this fact the present study confirmed the efficacy of PAA relative to IDU in the treatment of herpetic keratitis in the rabbit. In addition it showed that PAA is nontoxic to the eye and superior to IDU in preventing herpes virus replication in vivo. Therefore we believe that additional studies, including a controlled clinical trial in man, is now justified in view of the promising results both in vitro and in vivo.

This study was made possible by grant No. 015-0824 from the Swiss Fund for Ophthalmic Research. The interest and support of Professor H. Zauberman, head of the Department of Ophthalmology, Hadassah University Hospital, Jerusalem, is gratefully acknowledged.

\section{References}

Becker, Y., Asher, Y., Cohen, Y., Weinberg-Zahlering, E., and Shlomai, J. (1977). Antimicrobial Agents and Chemotherapy. In press.

Carroll, T. M., Martola, E. L., Laibson, P. R., et al. (1967). American Journal of Ophthalmology, 63, 103.

Cheng, Y. C., Neenan, J. P., Goz, B., et al. (1975). Annals of the New York Academy of Sciences, 255, 332.

Coleman, V. R., Tsu, E., and Jawetz, E. (1968). Proceedings of the Society for Experimental Biology and Medicine, 129, 761.

Gerstein, D. D., Dawson, C. R., and Oh, J. O. (1975). Antimicrobial Agents and Chemotherapy, 7, 285.

Hay, J., and Subak-Sharpe, J. (1976). Journal of General Virology, 31, 145.

Hyndiuk, R. A., Hull, D. S., Schultz, R. O., et al. (1972). American Journal of Ophthalmology, 79, 655.

Jawetz, E., Coleman, V. R., Dawson, C. R., and Thygeson, P. (1970). Annals of the New York Academy of Sciences, 173, 282.

Kaufman, E. H., Nesburn, A. B., and Malone, E. D. (1961). Archives of Ophthalmology, 67, 583.

Kaufman, H. E., Martola, E. L., and Dohlman, G. (1962). Archives of Ophthalmology, 68, 235.

Lahav, M., Dueker, D., Bhatt, P. N., and Albert, D. M. (1975). Archives of Ophthalmology, 93, 207.

Leinbach, S. S., Reno, J. M., Lee, L. F., Isabele, A. F., and Boezi, J. A. (1976). Biochemistry, 15, 426.

Levitt, J., and Becker, Y. (1967). Virology, 31, 129.

Mao, J. C. H., and Robishaw, E. E. (1975). Biochemistry, 14, 5475.

Meyer, R. F., Varnell, E. D., and Kaufman, H. E. (1976). Antimicrobial Agents and Chemotherapy, 9, 308.

O'Day, D. M., Pourier, R. H., Jones, D. B., and Elliott, J. H. (1976). American Journal of Ophthalmology, 81, 642.

O'Day, D. M., and Jones, B. R. (1977). Clinical Ophthalmology. In press. Harper and Row, New York.

Overby, L. R., Robishaw, E. E., Schleicher, J. B., et al. (1974). Antimicrobial Agents and Chemotherapy, 6, 360.

Peterson, A., and Jones, B. R. (1967). Transactions of the Ophthalmological Societies of the United Kingdom, 87, 59.

Shipkovitz, N. R., Bower, R., Appell, R., Nordeen, C., et al. (1973). Applied Microbiology, 26, 264. 